\title{
Hospital Utilization after the Epidemic
}

\author{
Ronald Lagoe*, Bella Lagoe, Shelly Littau \\ Hospital Executive Council, Syracuse, NY, USA \\ Email: *Hospexcl@cnymail.com
}

How to cite this paper: Lagoe, R., Lagoe, B. and Littau, S., (2021) Hospital Utilization after the Epidemic. Case Reports in Clinical Medicine, 10, 92-98.

https://doi.org/10.4236/crcm.2021.104011

Received: March 12, 2021

Accepted: April 11, 2021

Published: April 14, 2021

Copyright () 2021 by author(s) and Scientific Research Publishing Inc. This work is licensed under the Creative Commons Attribution International License (CC BY 4.0). http://creativecommons.org/licenses/by/4.0/

\section{Open Access}

\begin{abstract}
This study focused on hospital utilization for adult medical-surgical patients in Syracuse, New York as the census peaked then declined between December 2020 and February 2021. The initial analysis demonstrated that the adult medical-surgical census including Coronavirus patients declined by 8.1 percent during January and February 2021. The study data also demonstrated that the adult medical-surgical census of the combined hospitals increased as the numbers of virus patients declined. The inpatient census at the end of February 2021 was 3.6 percent below the level for February 2019 and 15.0 percent below the level for February 2020. This suggested a range between 3.6 and 15.0 percent below those in previous years for medical-surgical planning after the epidemic.
\end{abstract}

\section{Keywords}

Hospitals, Coronavirus, Inpatient Hospital Beds

\section{Introduction}

In recent years, the utilization of health care in the United States has undergone substantial changes. These developments have resulted from alterations in the delivery of care in local communities, as well as from new clinical factors [1].

In this period, the collection of health care data has struggled to keep up with the delivery of care. Providers of care, in particular, have worked to produce information that accurately characterizes the utilization of services and is useful for planning services [2].

This process has been especially important for health care planners. Changes in services have sometimes left these professionals behind, rather than ahead of, developments in the field.

Probably the most important of these developments has been the spread of the Coronavirus. The advent of this organism has challenged providers of care to assess the existing system of care and plan for changes. An important part of this 
process has been the quantification of the utilization of care.

Current experience suggests that, in many communities, health care providers have not been able to plan accurately for the impact of this epidemic. The onset of the virus in the initial months of 2020 has been a challenge for all hospitals and other providers. Because of the size of the epidemic, hospitals and other providers in the United States could not have been expected to predict its arrival [3] [4] [5].

At the same time, the impact of the Coronavirus on health care utilization at the community level over time has also been unpredictable. The use of major inpatient services such as adult surgery and adult medicine changed as the epidemic has developed. These changes have made it difficult to predict utilization of services and plan to address them [6] [7].

This study identified developments in the utilization of inpatient adult surgery and adult medicine in the hospitals of Syracuse, New York between December 2020 and February 2021. It suggested issues related to the planning and management of these services at the community level.

\section{Population}

This study focused on inpatient utilization in the hospitals of Syracuse, New York. These facilities include Crouse Hospital (17,204 discharges excluding well newborns-2020), St. Joseph's Hospital Health Center (21,328 inpatient discharges-2020), and Upstate University Hospital (30,988 inpatient discharges2020).

The Syracuse hospitals provide a full range of acute care services to an immediate service area of approximately 600,000 . They also provide tertiary, referral center services to the Central New York Health Service Area with a population of approximately $1,400,000$.

Historically, the Syracuse hospitals have worked cooperatively to improve the efficiency and outcomes of care in their service area. A number of these efforts have been developed through the Hospital Executive Council [8].

\section{Method}

This study focused on inpatient adult medicine and surgery utilization in the combined hospitals between December 2020 and February 2021. This was the most recent period of the Coronavirus epidemic in the service area of the hospitals.

The study was based on daily information for adult medicine and adult surgery, the largest inpatient services operated by the hospitals. These services were defined as all inpatient care excluding pediatrics, obstetrics, newborns and mental health.

Data for the study were collected by the Hospital Executive Council. They were based on daily information collected from the hospitals. This information was based on daily census reports developed by each of the hospitals. The study 
information was not based on abstracted medical record data because the data require at least 28 days to be completed in the combined hospitals.

Consent for use of these data was provided by the hospitals in the Business Associate Agreements with the Hospital Executive Council. This mechanism is also employed to provide ethics approval from the hospitals for multihospital studies.

Analysis of the study data focused on the adult medical-surgical inpatient census of the hospitals with and without Coronavirus patients between December 1, 2020 and February 28, 2021. Patients receiving intensive care were included in the data.

For the period of the data, inpatient census levels were identified by week during the three-month period. These levels were based on the combined inpatient censuses of the three acute care facilities.

These analyses suggested an approach to comparison of hospital adult medical-surgical census levels based on the same inpatient populations by week for three years at the community level. Through this approach, the impact of demographic and institutional variables was avoided.

The weekly census levels for the combined hospitals for December 2018February 2019, December 2019-February 2020, and December 2020-February 2021 were compared. The initial analysis was based on data for the December 2018-February 2019 and December 2019-February 2020, compared with data for December 2020-February 2021 including Coronavirus patients. The second analysis was based on December 2018-February 2019 and December 2019February 2020 compared with data for December 2020-February 2021 excluding Coronavirus patients.

The comparisons involving data that included and excluded coronavirus patients were developed in an effort to evaluate hospital adult medical-surgical census levels as numbers of coronavirus patients declined during the time period of the study and going forward.

In recent weeks, the numbers of these patients in the Syracuse hospitals have declined substantially. Between December 23, 2020 and February 25, 2021, the weekly inpatient Coronavirus census of the combined hospital fell from 350 to 55 patients.

These comparisons of inpatient census levels made it possible to suggest future inpatient utilization of the combined hospitals as the impact of the epidemic on the inpatient census reached a minimum. The data suggested future utilization of the hospitals based on major adult medicine and adult surgery populations.

\section{Results}

The initial component of the analysis focused on inpatient adult medical-surgery levels in the Syracuse hospitals including Coronavirus patients between December 1, 2020 and March 1, 2021. Relevant data are summarized in Figure 1. 


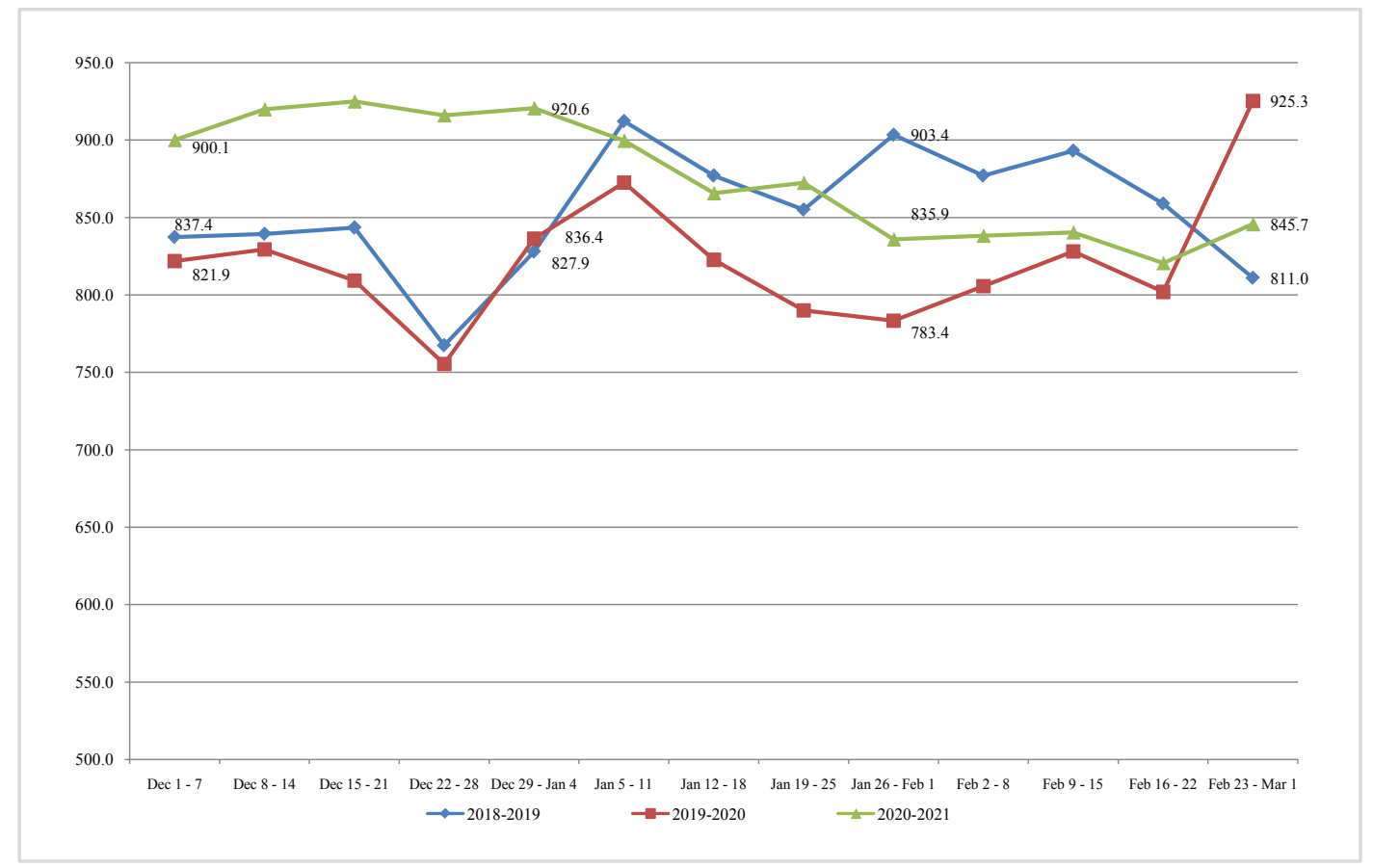

Figure 1. Hospital inpatient average daily census by week, adult medical/surgical including ICU/CCU, syracuse hospitals, December 2018-March 1, 2021.

The study data demonstrated that, during this period, the weekly census including Coronavirus patients ranged from 900.1 to 845.7 in 2020-2021, compared with 821.9 - 925.3 in 2019-2020 and 837.4 - 811.0 in 2018-2019. At the end of the three-month period, the weekly medical-surgical census levels were 925.3 for 2020 and 845.7 for 2021.

This comparison indicated the Coronavirus patients were responsible for an important part of the inpatient census during this period. As the weekly Coronavirus census for the combined hospitals declined by more than 200 patients during January and February 2021, the combined adult medical-surgical census also declined. This development included the largest reduction in almost twelve months. This occurred as the medical-surgical census levels for the same months in the two previous years were increasing and declining over short periods of time. The data indicated that the combined adult medical-surgical census levels including the Coronavirus reached 845.7 at the end of February 2021 and 925.3 at the end of February 2020. The 2021 census included 45 remaining Coronavirus patients.

Based on this information, the data suggested that future adult medical-surgical census levels of the hospitals would be approximately 845 - 925 patients. This projection was based on a remaining Coronavirus census of approximately 50 patients.

The second component of the analysis focused on weekly inpatient adult medical-surgical levels in the Syracuse hospitals between December 2020 and February 2021 excluding Coronavirus patients. Relevant data are summarized in Figure 2. 


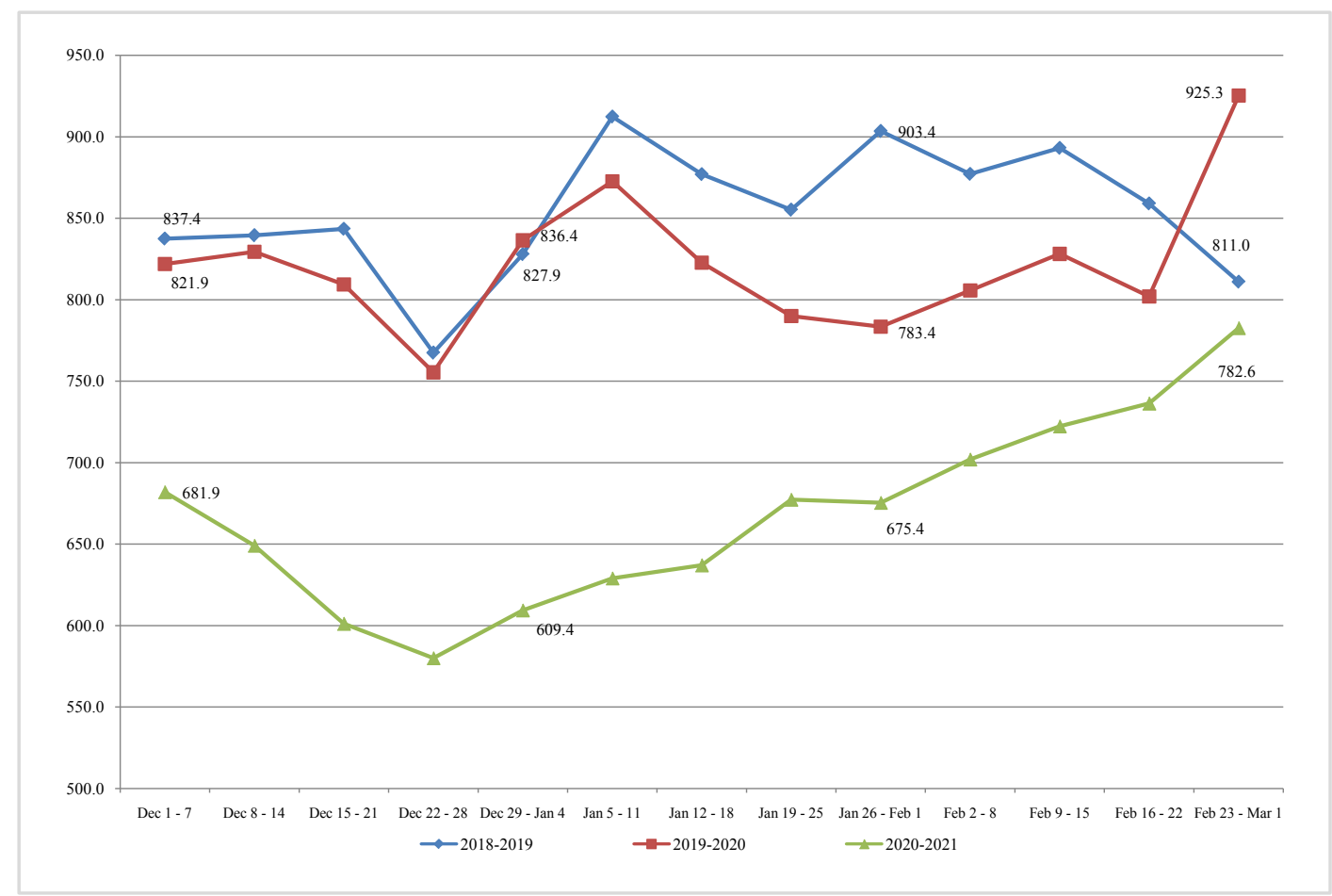

Figure 2. Hospital inpatient average daily census by week, adult medical-surgical including ICU/CCU, excluding COVID, syracuse hospitals, December 2018-March 1, 2021.

This information included weekly inpatient census data for December 2018February 2019, December 2019-February 2020, and December 2020-February 2021. All of these weekly time periods excluded Coronavirus patients. The first two occurred before the Coronavirus arrived in Syracuse. Coronavirus patients were excluded from the third. For comparison purposes, data for December 2018-February 2019 and December 2019-February 2020 were identical to those in Figure 1.

These data demonstrated that weekly inpatient data for December 2020February 2021 excluding Coronavirus patients underwent a substantial increase in utilization for this population. Between December 22, 2020 and March 1, 2021, the weekly average inpatient census rose from 590.0 to 782.6 patients. This amounted to an increase of approximately 192 patients or 33 percent.

Compared with the data in Figure 1, this information demonstrated that, as the weekly inpatient Coronavirus census in the Syracuse hospitals was declining during January and February 2021, the inpatient census excluding this population was increasing. The amount of this increase offset most of the decline in the adult medical-surgical population including the virus.

These data suggested that, as the virus population declined, utilization in the hospitals compensated for this change with regular adult medicine and adult surgery admissions. By the end of February 2021, a census of fewer than $50 \mathrm{Co}-$ ronavirus patients remained. Most of the reduction that resulted from the decline in the census during the epidemic had been offset. 
This information indicated that, at the end of February 2021, the weekly inpatient adult medical-surgical census of the Syracuse hospital excluding Coronavirus patients reached 782.6. This level was between 30 patients, or 3.6 percent, below the level for the same point in 2019 and 142 patients, or 15 percent, below the level for the same point in 2020. This amounted to a range for planning adult medical-surgical inpatient services excluding Coronavirus patients.

\section{Discussion}

In the United States, the Coronavirus epidemic has had a major impact on hospital utilization at the community level. In 2020, it was responsible for major increases in hospital utilization throughout the nation.

As the epidemic winds down, there are important opportunities for analyzing its impact. Available data can be employed to plan for hospital utilization in the future.

The study focused on hospital census including Coronavirus patients for adult medical-surgical inpatients in the hospitals of Syracuse, New York as utilization peaked, then declined during December 2020, January 2021, and February 2021. Data for the same months in 2018 and 2019 were included for comparison purposes.

The initial component of the analysis demonstrated that the inpatient adult medical-surgical census including Coronavirus patients declined by more than 75 patients during January and February 2021. This occurred as the inpatient censuses of the combined hospitals in previous years were relatively stable.

Perhaps most importantly, the study data also demonstrated that the inpatient adult medical-surgical census of the combined hospitals excluding Coronavirus patients increased as the numbers of virus patients were declining during January and February 2021. This increase apparently resulted from adult medicine and adult surgery patients offsetting the decline of those with the diagnosis.

The increase in the adult medical-surgical census without the virus did not totally offset the decline in the census that resulted from fewer virus patients. The difference between the inpatient census levels at the end of February 2021 and the census levels in 2019 and 2020 was between 3.6 and 15.0 percent. Going forward, this suggested a range for adult medical-surgical planning between 3.6 and 15.0 percent below those in previous years.

The analysis used in this study could also be applied to additional utilization data. These could include hospital discharges, hospital lengths of stay, and emergency department utilization. A combination of these indicators might be useful.

This information could be developed and used to plan the use of health care services at a relatively small expense. It could take advantage of cooperation among hospitals to address this objective.

The study data suggest that, because of the importance of inpatient adult medicine and surgery to inpatient hospitals, planning for services in the future 
should focus on remaining adult medical-surgical patients as the epidemic winds down. Such an approach can help health care providers anticipate and address future utilization issues.

\section{Conflicts of Interest}

The authors declare no conflicts of interest regarding the publication of this paper.

\section{References}

[1] Dentzler, S. (2011) Urgent Measures for an Old Problem. Health Affairs, 30, 1626. https://doi.org/10.1377/hlthaff.2011.0961

[2] Goozner, M. (2020) Big Data's Role in Addressing COVID-19. Modern Healthcare, $50,22$.

[3] Brady, M. (2020) Rolling Back Relief Will Be Tricky for Providers, Industry. Modern Healthcare, 50, 8-9.

[4] Livingston, S. (2020) Providers Sideline Employees, Cut Pay as Pandemic Saps Revenue. Modern Healthcare, 50, 6-7.

[5] Dasak, P., Keusch, G., Phalen, A., Johnson, C. and Osterholm, M. (2021) Infectious Disease Threats: A Rebound to Resilience. Health Affairs, 40, 208-211. https://doi.org/10.1377/hlthaff.2020.01544

[6] Bannow, T. (2021) A Tentative Hello to 2021. Modern Healthcare, 1, 18-19.

[7] Johnson, S. (2021) Will COVID-19 Be the Catalyst for Creating a More Sustainable Healthcare System? Modern Healthcare, 51, 12-14.

[8] Lagoe, R., Pasinski, T., Kronenberg, P., Quinn, T. and Schaengold, P. (2006) Linking Health Services at the Community Level. Canada Healthcare Quarterly, 9, 60-65. https://doi.org/10.12927/hcq..18229 